\title{
Determinants of acute events leading to mortality after shunt procedure in univentricular palliation
}

Tomislav Santro, MD, ${ }^{\mathrm{a}}$ Yves d'Udekem, MD, PhD, ${ }^{\mathrm{b}}$ Diana Zannino, MS, ${ }^{\mathrm{c}}$ Ben Hobbes, MD, Igor E. Konstantinov, $\mathrm{MD}, \mathrm{PhD},{ }^{\mathrm{b}}$ Christian Brizard, $\mathrm{MD},{ }^{\mathrm{b}}$ and Johann Brink, $\mathrm{MD}^{\mathrm{b}}$

\section{ABSTRACT}

Objective: The study objective was to identify determinants of adverse outcomes in patients undergoing univentricular palliation after the shunt procedure.

Methods: We performed a retrospective study of patients with univentricular lesions undergoing modified Blalock-Taussig shunt and central shunt placement, with or without concomitant Norwood/Damus-Kaye-Stansel procedures, between 2004 and 2014.

Results: Overall, 246 patients were included, with 150 patients undergoing concomitant Norwood/Damus-Kaye-Stansel procedure. The 30-day and inhospital mortality were $7.3 \%$ and $14.6 \%$, respectively. Progression to bidirectional cavopulmonary connection was achieved in $76 \%$ of patients. Acute events occurred in 66 patients $(27 \%$ ), with 42 having an acute event in the first 72 hours postoperatively. Of all in-hospital deaths, $75 \%$ had preceding acute events. On multivariable analysis, the risk factor for 30-day or in-hospital mortality was the incidence of an acute event (odds ratio [OR], 13.5; 95\% confidence interval [CI], 5.51-36.4; $P<.001)$. Postoperative $\mathrm{pH}$ was associated with fewer acute events (OR, 0.61 per 0.1 unit increase; $95 \%$ CI, 0.45-0.82; $P=.002)$. Risk factors for shunt thrombosis associated with an acute event were increased postoperative hematocrit (OR, 2.12 per 0.1 unit increase; 95\% CI, 1.01-4.58; $P=.049)$ and 3.0-mm shunt size (OR, 3.78; 95\% CI, 1.47-10.6; $P=.007)$. Damus-Kaye-Stansel/Norwood procedure, shunt type, morphology, and extracardiac or genetic anomaly were not risk factors for mortality or acute events.

Conclusions: More than one-fifth of patients shunted during univentricular palliation die before the second stage. The majority of these deaths are associated with acute events occurring early after surgery. Strategies to improve survival should focus on prevention and management of acute events. ( $\mathrm{J}$ Thorac Cardiovasc Surg 2019;158:1144-53)

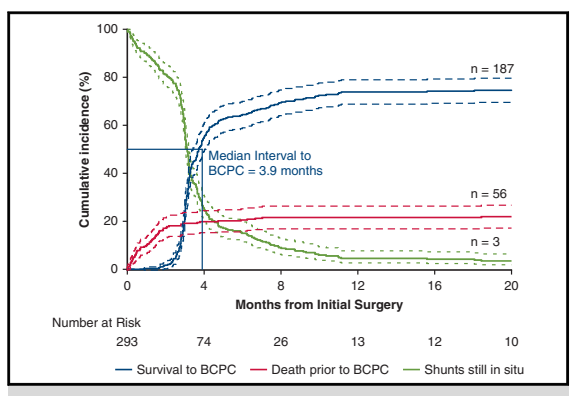

Cumulative incidence $(\%)$ of progression to BCPC following shunt procedure.

\section{Central Message}

More than one-fifth of patients shunted during univentricular palliation die before the second stage. The majority of these deaths are associated with an acute event occurring early after surgery.

\section{Perspective}

S-PA shunts are fraught with danger, especially in the early postoperative period, with contributing factors remaining poorly understood. Acute events are implicated in the majority of deaths and are largely associated with perioperative factors. Strategies to improve outcomes should focus on the perioperative period and the prevention and management of acute events.

See Commentaries on pages 1154 and 1156.
From the a Department of Pediatrics, Faculty of Medicine, The University of Melbourne, Melbourne, Australia; ' Department of Cardiac Surgery, The Royal Children's Hospital, Melbourne, Australia; and ${ }^{\mathrm{c}}$ Clinical Epidemiology and Biostatistics Unit, Murdoch Children's Research Institute, Melbourne, Australia. Read at the 98th Annual Meeting of The American Association for Thoracic Surgery, San Diego, California, April 28-May 1, 2018.

Received for publication April 29, 2018; revisions received March 26, 2019; accepted for publication March 30, 2019; available ahead of print July 24, 2019

Address for reprints: Johann Brink, MD, Department of Cardiac Surgery, The Royal Children's Hospital, 50 Flemington Rd, Parkville, 3052, Australia (E-mail: johann. brink@rch.org.au).

0022-5223/\$36.00

Crown Copyright $\odot 2019$ Published by Elsevier Inc. on behalf of The American Association for Thoracic Surgery

https://doi.org/10.1016/j.jtcvs.2019.03.126
Systemic-to-pulmonary artery (S-PA) shunts are palliative surgical procedures performed in isolation or concomitantly as part of the Norwood/Damus-Kaye-Stansel (DKS)

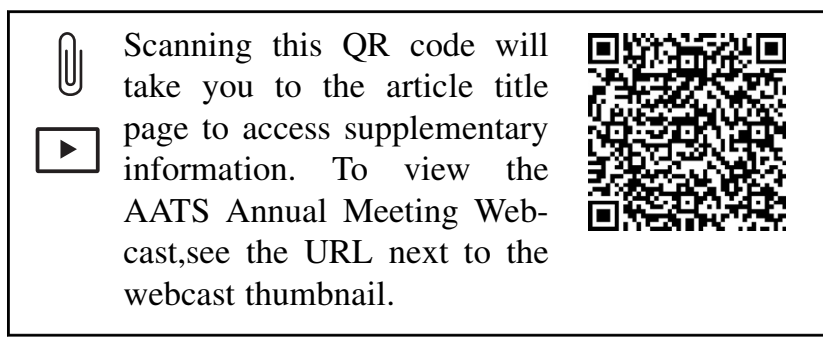




$$
\begin{aligned}
& \text { Abbreviations and Acronyms } \\
& \begin{aligned}
\text { BCPC } & =\text { bidirectional cavopulmonary connection } \\
\text { CI } & =\text { confidence interval } \\
\text { CPB } & =\text { cardiopulmonary bypass } \\
\text { DKS } & =\text { Damus-Kaye-Stansel } \\
\text { ECMO } & =\text { extracorporeal membrane oxygenation } \\
\text { IQR } & =\text { interquartile range } \\
\text { MBTS } & =\text { modified Blalock-Taussig shunt } \\
\text { OR } & =\text { odds ratio } \\
\text { S-PA } & =\text { systemic-to-pulmonary artery } \\
\text { VAD } & =\text { ventricular assist device }
\end{aligned}
\end{aligned}
$$

procedure, forming the cornerstone of modern palliative surgery in congenital heart disease. However, S-PA shunts are fraught with significant morbidity and mortality. Previous studies assessing outcomes in univentricular circulations reported in-hospital mortality rates of $7.2 \%$ to $19 \%$, with similar trends after hospital discharge. ${ }^{1-7}$ Shunt-related complications in univentricular cohorts have been estimated to occur in up to $15 \%$ of patients, with shunt thrombosis and stenosis, pulmonary artery stenosis, and overcirculation identified as key contributors postoperatively. ${ }^{8}$

Despite these pitfalls, shunts remain a necessity of palliative therapy in univentricular anomalies. Although attempts have been made to identify predictors of adverse outcomes after shunt procedures, these continue to remain poorly understood and mitigated, and further research is required to improve current practice. We evaluated morbidity and mortality in children destined for univentricular palliation to identify predictors of adverse outcomes after the shunt procedure.

\section{MATERIALS AND METHODS \\ Study Design}

A retrospective analysis of children destined for univentricular circulations who underwent S-PA shunt procedures between 2004 and 2014 was conducted at The Royal Children's Hospital, Melbourne, Australia. Inclusion criteria were shunt procedures performed in isolation or as part of concomitant procedures at initial surgery. Right ventricle-pulmonary artery conduits were excluded. Institutional ethics approval was granted.

Primary end points included 30-day mortality, in-hospital mortality, and "acute events." Acute events were defined as any postoperative event leading to a near-death experience or cardiac arrest, and required emergency chest reopening after sternal closure, extracorporeal membrane oxygenation (ECMO), ventricular assist device (VAD), or shunt reintervention. Shunt-related complications resulting in acute events included shunt thrombosis, shunt stenosis, pulmonary artery stenosis, and pulmonary overcirculation. Shunt thrombosis is defined by the presence of thrombus at the time of surgical shunt revision or echocardiography, or based on a high index of clinical suspicion during an event. Shunt and pulmonary artery stenosis are defined as kinking/compression confirmed by echocardiography, angiography, computed tomography scan, or during surgical revision. Pulmonary overcirculation was clinically defined on the basis of persistently elevated oxygen saturation greater than $85 \%$ and requirement for diuretics or afterload reduction to maintain hemodynamic stability.
Secondary end points included interstage mortality, survival and progression to bidirectional cavopulmonary connection (BCPC), and cohort progression to Fontan completion, including overall survival. Interstage mortality was defined as death after hospital discharge after initial shunt surgery but before BCPC.

\section{Surgical and Medical Management of Shunts}

Shunts were constructed with an interposition polytetrafluoroethylene (Gore-Tex) vascular graft (WL Gore and Associates, Inc, Azusa, Calif). Surgeon's discretion of shunt type and size was based on patient weight, cardiac, and vasculature anatomy. Shunts included modified BlalockTaussig shunt (MBTS) and central shunts. Central shunts were constructed according to Hillel Laks' technique previously described. ${ }^{9,10}$ Shunt procedures were performed with or without cardiopulmonary bypass (CPB). CPB was required in patients who needed concomitant procedures or experienced hemodynamic instability. Most patients who required $\mathrm{CPB}$ received tranexamic acid or aprotinin intraoperatively. Tranexamic acid was used in the earlier era and replaced with aprotinin. The patent ductus arteriosus was ligated in all patients after shunt completion. To prevent overcirculation, some shunts were reduced intraoperatively by wrapping. Shunt wrapping was performed by longitudinally opening another polytetrafluoroethylene (Gore-Tex) graft of equal diameter, wrapping it around the original shunt, and suturing the sides together to restrict shunt flow. Immediately after surgery, patients were anticoagulated with a heparin infusion (10-20 U/kg) unless excessive bleeding occurred. Oral aspirin was administered to all patients once enterally tolerated. Clopidogrel was added for those with 3.0-mm and 3.5-mm wrapped shunts.

During acute events, patients with suspected shunt thrombosis received a loading dose of heparin $(100 \mathrm{U} / \mathrm{kg})$ and underwent shunt milking. Shunt milking was performed by occluding the proximal end of the shunt with forceps, and with another set of forceps, gently clamping the shunt and moving from a proximal to distal direction to expel any possible sludge within the lumen of the shunt to regain patency. If no sustained clinical stability was achieved, patients underwent immediate shunt replacement. Patients with wrapped shunts who experienced ongoing desaturations had their shunts unwrapped, and those who experienced pulmonary overcirculation had their shunts wrapped.

\section{Statistical Analysis}

Patient data were collected from an internal database and electronic and paper medical records. Analysis of data was completed using R Version 3.5.1 (R Foundation, Vienna, Austria, http://www.r-project.org). Univariable logistic regression analysis was used for risk-factor analysis for 30-day or in-hospital mortality. Factors with a $P$ value less than .1 were considered in the multivariable analysis. Backward selection was used to reduce the number of factors until all included factors were significant. Collinearity in the multivariable model was assessed using the variance inflation factor. Cumulative incidence of progression to BCPC was completed using a competing survival risk analysis with death as the competing risk. All data for continuous variables are presented as mean \pm standard deviation or median (interquartile range [IQR], quartile 1 to quartile 3) where appropriate. Odds ratios (OR) are presented with $95 \%$ confidence intervals (CIs).

\section{RESULTS}

\section{Demographics}

A summary of patient demographics and operative characteristics is listed in Table 1. A total of 246 patients underwent univentricular shunt palliation; 162 were male $(66 \%)$. In this cohort, 17 had right atrial isomerism, and 11 had left atrial isomerism. A total of 158 patients $(64 \%)$ had an 
TABLE 1. Patient demographics and operative characteristics

\begin{tabular}{|c|c|c|c|c|c|c|c|c|c|c|}
\hline Characteristics & Total & HLHS & AVSD & PA-IVS & $\begin{array}{c}\text { Tricuspid } \\
\text { atresia }\end{array}$ & DILV & DORV & PA-VSD & $\begin{array}{l}\text { Ebstein's } \\
\text { anomaly }\end{array}$ & Other \\
\hline \multicolumn{11}{|c|}{ Patient demographics } \\
\hline No. & 246 & $98(40)$ & $37(15)$ & $33(13)$ & $23(9)$ & $15(6)$ & $12(5)$ & $6(2)$ & $5(2)$ & 17 (7) \\
\hline Age, d & $4(2-8)$ & $2(2-3)$ & $5(4-12)$ & $6(2-14)$ & $6(4-13)$ & $7(4-12)$ & $5(3-7)$ & $6(4-10)$ & $6(3-7)$ & $7(3-10)$ \\
\hline Weight, kg & $3.4 \pm 0.8$ & $3.4 \pm 0.5$ & $3.7 \pm 1.6$ & $3.2 \pm 0.6$ & $3.3 \pm 0.5$ & $3.3 \pm 0.5$ & $3.4 \pm 0.5$ & $3.1 \pm 0.4$ & $2.9 \pm 0.6$ & $3.4 \pm 0.4$ \\
\hline $\begin{array}{l}\text { Associated } \\
\text { cardiac } \\
\text { diagnosis }\end{array}$ & $158(64)$ & $61(63)$ & $33(89)$ & $15(45)$ & $11(48)$ & $13(87)$ & $10(83)$ & $6(100)$ & - & $9(53)$ \\
\hline $\begin{array}{l}\text { Genetic or } \\
\text { extracardiac } \\
\text { anomaly }\end{array}$ & $57(23)$ & $15(15)$ & $24(65)$ & $5(15)$ & $3(13)$ & $2(13)$ & $1(8)$ & $2(33)$ & - & $5(29)$ \\
\hline \multicolumn{11}{|l|}{ Shunt type } \\
\hline MBTS & $228(93)$ & $98(100)$ & $26(70)$ & $29(88)$ & $22(96)$ & $14(93)$ & $12(100)$ & $6(100)$ & $4(80)$ & $17(100)$ \\
\hline Central & $18(6)$ & - & $11(30)$ & $4(12)$ & $1(4)$ & $1(7)$ & - & - & $1(20)$ & - \\
\hline \multicolumn{11}{|l|}{ Shunt size } \\
\hline $3.0 \mathrm{~mm}$ & $92(37)$ & $44(45)$ & $14(38)$ & $9(27)$ & $8(35)$ & $4(27)$ & $2(17)$ & - & $4(80)$ & $7(42)$ \\
\hline $3.5 \mathrm{~mm}$ & $140(57)$ & $53(54)$ & $19(51)$ & $20(61)$ & $15(65)$ & $9(60)$ & $9(75)$ & $5(83)$ & - & $10(59)$ \\
\hline $4.0 \mathrm{~mm}$ & $13(5)$ & $1(1)$ & $3(8)$ & $4(12)$ & - & $2(13)$ & $1(8)$ & $1(17)$ & $1(20)$ & - \\
\hline $5.0 \mathrm{~mm}$ & $1(0.5)$ & - & $1(3)$ & - & - & - & - & - & - & - \\
\hline $\begin{array}{l}\text { Shunt size/ } \\
\text { weight } \\
\text { ratio, } \mathrm{mm} / \mathrm{kg}\end{array}$ & $\begin{array}{c}1.00 \\
(0.92-1.09)\end{array}$ & $\begin{array}{c}0.95 \\
(0.90-1.06)\end{array}$ & $\begin{array}{c}1.00 \\
(0.92-1.09)\end{array}$ & $\begin{array}{c}1.09 \\
(0.98-1.15)\end{array}$ & $\begin{array}{c}1.02 \\
(0.95-1.08)\end{array}$ & $\begin{array}{c}1.06 \\
(0.97-1.08)\end{array}$ & $\begin{array}{c}1.05 \\
(0.92-1.11)\end{array}$ & $\begin{array}{c}1.15 \\
(1.07-1.24)\end{array}$ & $\begin{array}{c}1.07 \\
(1.00-1.08)\end{array}$ & $\begin{array}{c}1.00 \\
(0.91-1.07)\end{array}$ \\
\hline \multicolumn{11}{|l|}{$\begin{array}{l}\text { Operative } \\
\text { characteristics }\end{array}$} \\
\hline $\begin{array}{l}\text { Sternotomy/ } \\
\text { thoracotomy }\end{array}$ & $241 / 6$ & $98 / 1$ & $36 / 1$ & $30 / 3$ & $23 / 0$ & $15 / 0$ & $12 / 0$ & $6 / 0$ & $4 / 1$ & $17 / 0$ \\
\hline $\begin{array}{c}\text { Concomitant } \\
\text { surgery }\end{array}$ & $193(78)$ & 98 (100) & $22(60)$ & $16(48)$ & $14(61)$ & $14(93)$ & $7(58)$ & $5(83)$ & $3(60)$ & $14(83)$ \\
\hline $\mathrm{CPB}$ use & $222(90)$ & $98(100)$ & $33(89)$ & $20(61)$ & $21(91)$ & $14(93)$ & $11(92)$ & $5(83)$ & $4(80)$ & $16(94)$ \\
\hline
\end{tabular}

Variables are listed as the total number followed by percentage, except age, and shunt size/weight ratio, which are listed as median (quartile 1 - quartile 3 ) and weight ( \pm standard deviation). HLHS, Hypoplastic left heart syndrome; AVSD, atrioventricular septal defect; PA-IVS, pulmonary atresia with intact ventricular septum; DILV, double inlet left ventricle; $D O R V$, double outlet right ventricle; $P A-V S D$, pulmonary atresia with ventricular septal defect; $M B T S$, modified Blalock-Taussig shunt; $C P B$, cardiopulmonary bypass.

associated cardiac diagnosis that included total or partial anomalous pulmonary venous drainage, aortic arch hypoplasia or coarctation, inferior vena cava interruption, and coronary artery anomalies or sinusoids. Fifty-seven patients $(23 \%)$ had an extracardiac or genetic anomaly.

Preoperatively, 216 patients $(88 \%)$ received prostaglandin infusion until surgery. Additionally, 86 patients $(35 \%)$ required intubation and ventilatory support, and inotropic infusion was necessary in 79 patients $(32 \%)$. Preoperative ECMO was required in 3 patients $(1 \%)$.

\section{Initial Surgery}

Overall, 246 patients had shunt procedures at a median age of 4 days (IQR, 2-8). The mean weight was $3.4 \pm 0.8 \mathrm{~kg}$, with 10 patients $(4 \%)$ weighing less than $2.5 \mathrm{~kg}$. Sternotomy was performed in 241 patients (98\%). Shunts included 229 MBTS (217 right; 12 left) and 18 central shunts. Forty-one patients $(17 \%)$ had their shunts wrapped at the initial surgery. Concomitant procedures were performed in 193 patients: 96 Norwood procedures, 54 DKS procedures, 23 pulmonary artery plasty procedures, 22 valvuloplasty procedures, 17 atrial septectomy procedures (excluding those performed in Norwood/DKS), 4 right ventricular outflow tract augmentations, 3 total anomalous pulmonary venous drainage repairs, 2 unroofings of coronary sinus, 1 resection of atrial wall, 1 resection of atrial appendage, 1 ventricular septal defect enlargement, and 1 left subclavian artery reimplantation.

CPB was used in 222 patients $(90 \%)$, with a median of 161 minutes (IQR, 100-207) and median crossclamp time of 56 minutes (IQR, 12-80). In patients who did not undergo $\mathrm{CPB}$, heparin was administered at a mean dose of $111 \pm 56$ U/kg. During surgery, platelets were required in 153 patients $(62 \%)$ at a mean dose of $18 \pm 15 \mathrm{~mL} / \mathrm{kg}$. Clotting factors were required intraoperatively in 203 patients $(83 \%)$, with 178 patients requiring fresh-frozen plasma (mean $=87 \pm 35 \mathrm{~mL} / \mathrm{kg}$ ) and 77 patients requiring cryoprecipitate (mean $=12 \pm 8 \mathrm{~mL} / \mathrm{kg}$ ). Aprotinin and tranexamic acid were used in 126 patients $(51 \%)$ and 62 patients $(25 \%)$, respectively.

Intraoperatively, 165 patients $(67 \%)$ had their chest left open, of whom 140 patients underwent Norwood/DKS procedures. Seven patients $(3 \%)$ required ECMO and 6 
TABLE 2. Multivariable risk factors associated with 30-day and inhospital mortality, acute events, and shunt thrombosis associated with acute events

\begin{tabular}{|c|c|c|}
\hline Multivariable factors & OR $(95 \%$ CI) & $P$ value \\
\hline \multicolumn{3}{|l|}{ 30-d mortality } \\
\hline Incidence of an acute event & $6.57(2.28-21.8)$ & .001 \\
\hline $\begin{array}{l}\text { Preoperative hematocrit } \\
\text { (per 0.1-unit increase) }\end{array}$ & $0.32(0.12-0.77)$ & .017 \\
\hline $\begin{array}{l}\text { Immediate shunt revision postacute } \\
\text { event }\end{array}$ & $0.18(0.03-0.82)$ & .02 \\
\hline \multicolumn{3}{|l|}{ In-hospital mortality } \\
\hline Incidence of an acute event & $13.5(5.51-36.4)$ & $<.001$ \\
\hline CPB time (per 10-min increase) & $1.10(1.04-1.16)$ & .002 \\
\hline \multicolumn{3}{|l|}{ Acute events } \\
\hline $\begin{array}{l}\text { Postoperative APTT (per 10-unit } \\
\text { increase) }\end{array}$ & $1.12(1.04-1.20)$ & .002 \\
\hline $\begin{array}{l}\text { Preoperative hematocrit } \\
\text { (per 0.1-unit increase) }\end{array}$ & $0.62(0.40-0.94)$ & .03 \\
\hline $\begin{array}{l}\text { Postoperative } \mathrm{pH} \text { (per 0.1-unit } \\
\text { increase) }\end{array}$ & $0.61(0.45-0.82)$ & .002 \\
\hline \multicolumn{3}{|l|}{$\begin{array}{l}\text { Shunt thrombosis associated with } \\
\text { acute events }\end{array}$} \\
\hline 3.0-mm shunt size & $3.78(1.47-10.6)$ & .007 \\
\hline $\begin{array}{r}\text { Postoperative hematocrit } \\
\text { (per 0.1-unit increase) }\end{array}$ & $2.12(1.01-4.58)$ & .049 \\
\hline
\end{tabular}

$O R$, Odds ratio; $C I$, confidence interval; $C P B$, cardiopulmonary bypass; $A P T T$, activated partial thromboplastin time.

patients $(2 \%)$ required VAD support for failure to wean off $\mathrm{CPB}$ or hemodynamic instability.

\section{Mortality and Associated Risk Factors}

The 30-day mortality rate was $7.3 \%$ (18 patients), and inhospital mortality rate was $14.6 \%$ (36 patients). Median length of hospital stay was 32 days (IQR, 21-50), with 130 patients $(53 \%)$ staying more than 30 days. After hospital discharge, a further 20 patients $(8.1 \%)$ died before second-stage BCPC palliation (interstage mortality). Overall mortality was $30.9 \%$ (76 patients).

Multivariable risk factor analysis for 30-day and inhospital mortality is presented in Table 2 (Tables E1 and E2 show data inclusive of univariable analysis). Risk factors for 30-day or in-hospital mortality on multivariable analysis were $\mathrm{CPB}$ time (OR, 1.10 per 10 -minute increase; $95 \% \mathrm{CI}$, $1.04-1.16 ; P=.002)$ and incidence of an acute event (OR, 13.5 ; $95 \%$ CI, 5.51-36.4; $P<.001)$. Higher preoperative hematocrit was associated with reduced mortality (OR, 0.32 per 0.1 unit increase; $95 \% \mathrm{CI}, 0.12-0.77 ; P=.017)$.

\section{Acute Events}

Acute events occurred in 66 patients (27\%), with 42 of these patients $(64 \%)$ having an event within 72 hours after surgery. Of these 66 patients, $35(53 \%)$ died in- hospital or after discharge after an acute event. Of all in-hospital deaths, $75 \%$ had preceding acute events. Median length of stay for those who had an acute event was 38 days (IQR, 25-53). Of those 42 patients who had an acute event within the first 72 hours, $21(50 \%)$ died. In the remaining 24 patients who had an acute event after 72 hours, $14(58 \%)$ died. Independently, early acute events were not associated with 30-day or in-hospital mortality.

A summary of acute events is shown in Table 3. Of these 66 patients, $25(38 \%)$ required emergency chest reopening and $31(47 \%)$ required ECMO/VAD support. Shunt thrombosis was identified in 20 patients and pulmonary overcirculation in 5 patients. Shunt stenosis and pulmonary artery stenosis did not lead to acute events. Multivariable risk factor analysis for acute events is presented in Table 2 (Table E3 shows data inclusive of univariable analysis). Factors associated with acute events on multivariable analysis were prolonged activated partial thromboplastin time postoperatively (OR, 1.12 per 10 unit increase; $95 \% \mathrm{CI}$, $1.04-1.20 ; P=.002)$. Factors associated with fewer acute events were higher preoperative hematocrit (OR, 0.62 per 0.1 unit increase; $95 \% \mathrm{CI}, 0.40-0.94 ; P=.03$ ) and higher postoperative $\mathrm{pH}$ (OR, 0.61 per 0.1 unit increase; $95 \%$ CI, 1.04-1.20; $P=.002$ ).

Of the 66 patients who had an acute event, 15 required immediate shunt reintervention. These 15 patients required the following interventions: 14 shunt replacements of equal size, 2 shunt unwrappings, and 1 shunt type change. After an acute event, immediate shunt replacement was associated with less 30 -day mortality (OR, $0.18 ; 95 \% \mathrm{CI}, 0.03$ $0.82 ; P=.02)$. A further 16 patients who had an acute event also required shunt reinterventions at a later stage. Management included 8 shunt wrappings, 4 shunt replacements of equal size, 3 shunt unwrappings, 2 shunt upgrades, and 1 shunt type change.

Shunt thrombosis associated with acute events was identified in 20 patients at a median time of 43 hours (IQR, 4-161) postsurgery. Emergency chest reopening was required in 8 patients, and all patients underwent shunt milking. Management involved 10 immediate shunt replacements of equal size, 3 shunt unwrappings, and 1 shunt type change. One shunt of equal size was also replaced at a later stage. Of the 20 patients with suspected shunt thrombosis that resulted in an acute event, 7 (35\%) died. On multivariable analysis (Table 2), factors associated with shunt thrombosis associated with an acute event were 3.0-mm shunt size (OR, 3.78; 95\% CI, 1.47-10.6; $P=.007)$ and postoperative hematocrit (OR, 2.12 per 0.1 unit increase; 95\% CI, 1.01-4.58; $P=.049$ ) (Table E4 shows data inclusive of univariable analysis).

Pulmonary overcirculation associated with an acute event occurred in 5 patients at a median of 168 hours (IQR, 6-305) after surgery. Their management included 3 
TABLE 3. Summary of the causative factors of acute events in the postoperative period after initial shunt surgery

\begin{tabular}{lc}
\hline \multicolumn{1}{c}{ Causes of acute events } & No. of patients \\
\hline Shunt thrombosis & 22 \\
$\begin{array}{l}\text { Cardiac arrest/hemodynamic instability (not shunt } \\
\text { related, unclear cause) }\end{array}$ & 12 \\
\hline Pulmonary overcirculation & 5 \\
Rising lactate requiring circulatory support & 5 \\
\hline Pulmonary hypertensive event & 4 \\
\hline Myocardial dysfunction & 3 \\
\hline Pericardial tamponade & 3 \\
Unsuccessful chest closure & 3 \\
\hline Vasoplegia & 3 \\
\hline Sepsis & 2 \\
\hline Coronary steal (sinusoids) & 1 \\
\hline Electrolyte disturbance (hypermagnesemia) & 1 \\
\hline Failed ECMO decannulation & 1 \\
\hline Removal of left atrial line (bleeding) & 1 \\
\hline
\end{tabular}

ECMO, Extracorporeal membrane oxygenation.

emergency chest reopenings and 3 shunt wrappings, and 2 required ECMO/VAD support. Subsequently, 4 patients died $(80 \%)$.

\section{Shunt Reintervention}

Overall, 58 patients ( $24 \%$ ) required shunt reintervention. Reinterventions included 2 shunt replacements before completion of the initial surgery due to intraoperative shunt thrombosis. Postoperatively, 10 shunts were wrapped, 9 shunts were unwrapped, and 4 shunts were clipped (as part of ECMO strategy). Shunt replacement was required in 40 patients.

\section{Shunt Thrombosis and Pulmonary Overcirculation}

Overall, shunt thrombosis was suspected in 28 patients $(11.4 \%)$, of whom 20 had an acute event. Of these 28 patients, $12(43 \%)$ subsequently died. Pulmonary overcirculation was estimated in 38 patients (15.4\%), of whom 5 had an acute event. The majority of patients were managed medically with diuretics and afterload reduction. Of the 38 patients who experienced pulmonary overcirculation, 9 subsequently died $(24 \%)$.

\section{Other Complications}

Overall, pulmonary artery stenosis before BCPC was observed in 12 patients $(4.9 \%)$ and shunt stenosis in 10 patients $(4.1 \%)$. Twenty-two patients $(9 \%)$ had a neurologic injury, and 30 patients (12\%) developed necrotizing enterocolitis after shunt surgery.

\section{Norwood and Damus-Kaye-Stansel Exclusion}

To assess outcomes of S-PA shunts alone, patients who underwent Norwood or DKS were excluded for analysis, which resulted in 96 patients. Of these patients, 15 $(15.6 \%)$ had an in-hospital death and $9(9.4 \%)$ had an interstage mortality. Acute events occurred in 23 patients (24\%), of whom 6 had shunt thrombosis. On multivariable analysis, Norwood/DKS procedure was not associated with mortality or acute events (Tables E1-E3).

\section{Overall Cohort Progression}

Of the 246 patients, $187(76 \%)$ progressed to BCPC at a median interval of 3.9 months (Figure 1), and 128 patients $(52 \%)$ reached Fontan completion at a median of 4.7 years, with a total of 14 patients lost to follow-up throughout this period. One patient was unsuitable for completion and underwent transplantation. At the time of this study, 1 patient remains in shunt stage and 32 patients are currently in BCPC stage, awaiting Fontan completion. Overall estimated survival at 10 years is $68 \%(95 \% \mathrm{CI}, 62-74)$ (Figure 2).

\section{DISCUSSION}

Use of S-PA shunts in patients with congenital heart disease destined for univentricular palliation remains unavoidable and is increasing. ${ }^{11}$ This shift is attributed to the advances made in surgical techniques and perioperative management strategies in this difficult group of patients. However, despite these advances, morbidity and mortality of shunt procedures in isolation or part of complex procedures (Norwood/DKS) remain high. ${ }^{11}$ In our series, 30-day and in-hospital mortality were $7.3 \%$ and $14.6 \%$, respectively. These rates are consistent with previous univentricular studies reporting in-hospital mortality of $7.2 \%$ to $19 \%{ }^{1-7}$ Although not widely reported, interstage mortality rates of up to $14 \%$ have been estimated in mixed ventricle cohorts. ${ }^{5}$ Comparatively, rates in our study were $8.1 \%$, with shunt thrombosis the likely causative factor. With current anticoagulation strategies available, we have been unable to prevent this lethal complication, which emphasizes the continuing need for close interstage surveillance after discharge. Additionally, we have a policy of early elective BCPC at 3 months of age to reduce interstage mortality. Further, less than one-quarter of our cohort required shunt reintervention. Comparatively, rates of $8.4 \%$ to $17 \%$ have been reported, but these underestimate the reality because these studies often account for shunt replacements alone and do not include shunt wrappings/unwrappings. ${ }^{4,12-15}$ Of note, these findings enable surgeons to better inform families of the risks and outcomes for their child at the first stage of the univentricular palliative pathway. 


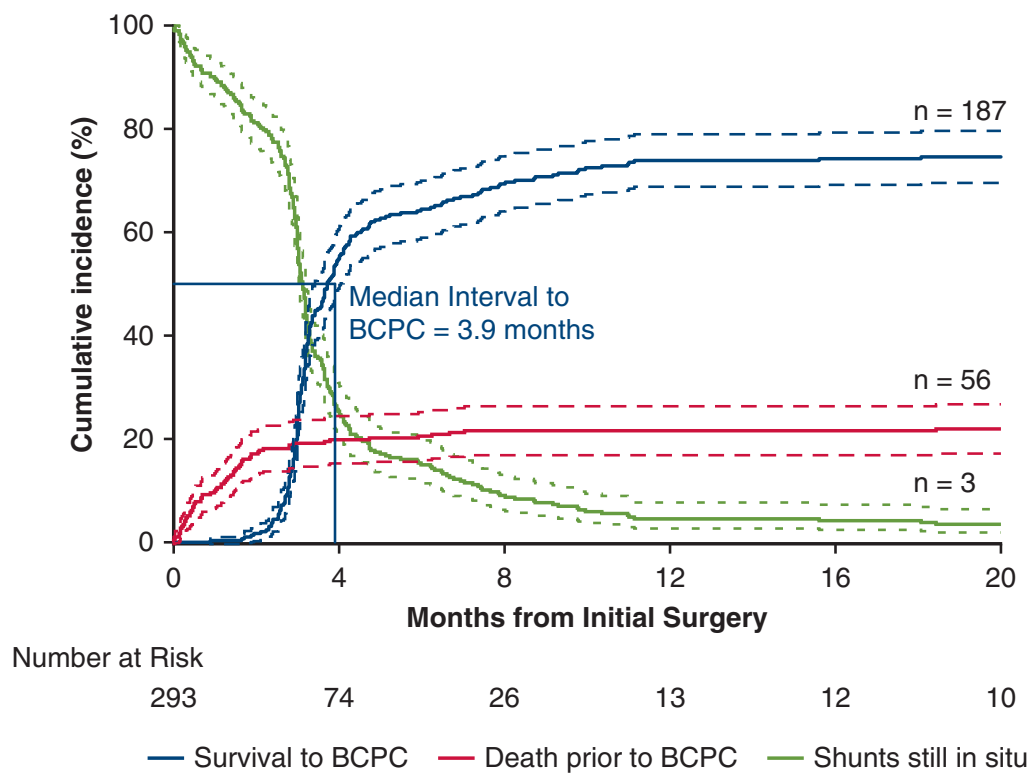

FIGURE 1. Cumulative incidence (\%) of progression to BCPC surgery was achieved at a median interval of 3.7 months after the initial shunt procedure. $B C P C$, Bidirectional cavopulmonary connection.

Unlike previous studies with mixed cohorts, patient factors such as age, morphologic diagnosis, associated cardiac diagnosis, heterotaxy syndrome, and extracardiac or genetic anomalies did not contribute to 30-day or inhospital mortality in this study. ${ }^{1,3,15-18}$ Unfortunately, preoperative mechanical ventilation, shock/acidosis, and ECMO use have been found to be associated with mortality. ${ }^{3,4,15,16}$ However, our study could not identify these risk factors on multivariable analysis. The use of prostaglandin in duct-dependent univentricular hearts is common, as seen in approximately $90 \%$ of our cohort. Ventilatory support for prostaglandin-induced apnea or pulmonary overcirculation may occur in these patients,

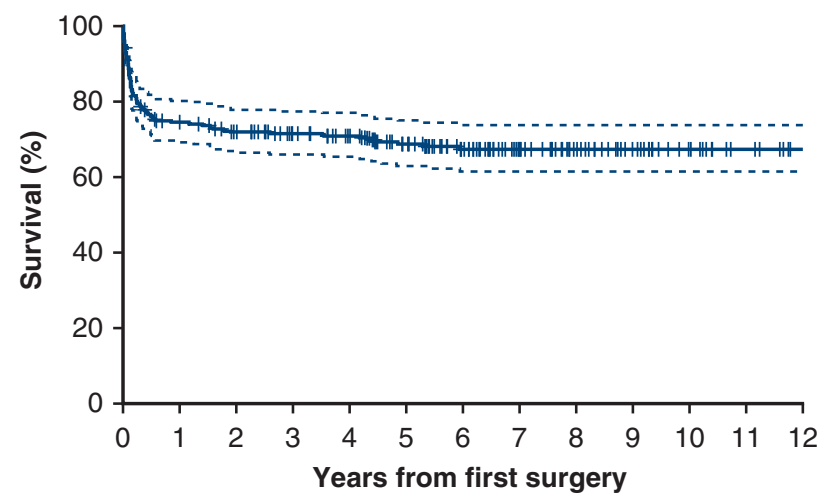

Number at risk

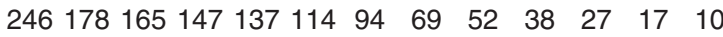

FIGURE 2. Overall cohort survival estimate (\%) after the initial shunt procedure. and one could hypothesize that preoperative ventilation or ECMO may be a means of recovering or protecting end-organ function in these neonates. The degree of endorgan damage may be a better surrogate for prediction of mortality than the mere presence of shock, ventilation, and ECMO preoperatively. However, because of small numbers, events, and the nature of our data, we are not able to substantially support this notion. Unlike other studies, our study did not find low weight and a larger shunt size/weight ratio to be associated with mortality on multivariable analysis. ${ }^{2,4,17}$ However, patients with 3.0-mm shunts were approximately 4 times more at risk to have thrombosis associated with an acute event. Traditionally, choosing the optimal shunt size seems essential and a difficult decision at the same time. Our team has opted for smaller shunts for many years to avoid overcirculation and volume loading of the right heart in hypoplastic left heart syndrome. ${ }^{19}$ Anecdotally, 4 of the 5 patients who had an acute event related to pulmonary overcirculation died, which we believe underlines how deleterious it may be to oversize the shunt in fragile neonates. In addition, unlike Alsoufi and colleagues, ${ }^{4}$ who demonstrated CPB use to be associated with mortality, we were unable to replicate use alone to be predictive of mortality. Instead, duration on CPB was associated with mortality, suggesting prolonged periods to have an impact on inflammatory and coagulation cascades of patients, ultimately contributing to their deaths. ${ }^{1}$ However, given that $90 \%$ of patients were operated on $\mathrm{CPB}$, we concede that comparisons and definitive conclusions are difficult to draw from this study. Although CPB is unavoidable in those undergoing 
Right ventricle-pulmonary artery shunt in first-stage palliation of hypoplastic left heart syndrome

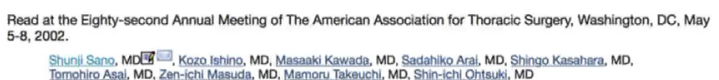

The Journal of Thoracic and Cardiovascular Surgery • Volume 126, Number 2505
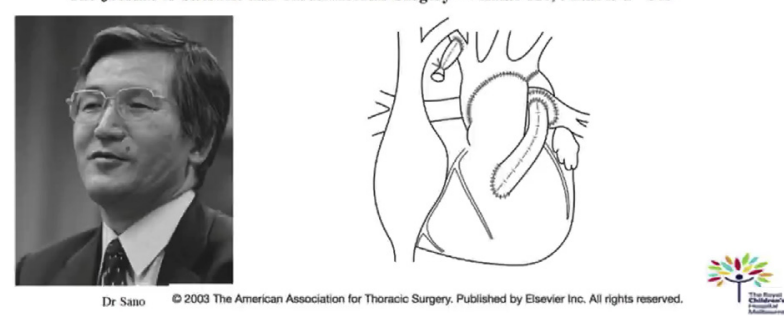

VIDEO 1. Determinants of acute events leading to mortality after the shunt procedure in univentricular palliation-AATS 2018. Note the presentation refers to a previous cohort of patients before the exclusion of those who underwent a right ventricle-pulmonary artery conduit due to their physiologic differences compared with other shunts. Video available at: https://www.jtcvs.org/article/S0022-5223(19)30979-1/fulltext.

concomitant surgery, closer perioperative surveillance may improve survival.

Interestingly, comparable rates of in-hospital mortality and acute events were observed in patients who had shunts in isolation compared with those in the spectrum of hypoplastic left heart syndrome undergoing complex Norwood/ DKS procedures. These findings are supported with similar long-term survival outcomes previously reported when comparing these 2 cohorts. ${ }^{6,20}$ Thus, although the more aggressive surgical procedure, it appears the procedure itself does not confer additional risks to mortality or subsequent postoperative complication but emphasizes the danger of shunt physiology in its own right.

To our knowledge, the concept of postoperative acute events or near-death experiences has not been examined collectively in univentricular patient cohorts (Video 1). Of those patients who died in hospital, three-quarters had an acute event. Strikingly, incidence of an acute event was associated with an approximately 14-fold increased risk of mortality, with approximately half of the patients who experienced an acute event requiring ECMO/VAD support, clearly representing a significant area of consideration in improving survival. Acute events were associated with prolonged activated partial thromboplastin time postoperatively. However, we believe this to be erroneous and may represent a surrogate variable of unclear significance. Higher preoperative hematocrit and postoperative $\mathrm{pH}$ were associated with fewer acute events. Higher hematocrit allows for greater oxygen carrying capacity, an advantage if no CPB is used. However, most shunts required $\mathrm{CPB}$ and therefore negate any clear conclusion. Postoperatively, higher $\mathrm{pH}$ contributes to reduction of pulmonary vascular resistance promoting shunt flow, which likely reduces risk of stasis-induced thrombosis and acute events. Perioperative strategies should aim to manage these patients with higher $\mathrm{pH}$ to improve outcomes. Although this may be true in smaller shunts, it may not be a valid argument in patients with pulmonary overcirculation who require management strategies to reduce pulmonary blood flow. In our study, a causative factor for a large number of acute events could not be identified with certainty. This may be due to the retrospective nature of the study or likely due to the numerous factors determining shunt physiology. It is possible that these variables may be associated with a poor cardiac output state. However, these data were not captured in this study. Therefore, for a given anatomic set-up (shunt size), early postoperative recognition of physiologic status of the circulation (balanced, over- or under-flow) may be more important to appropriately manage these patients to prevent acute events.

Shunt thrombosis was a significant contributor to acute events and mortality. Overall, the rate of thrombosis was $11.4 \%$, with the majority associated with acute events. Comparatively, others have reported rates of $5.5 \%$ to $15 \%$ in univentricular cohorts. ${ }^{5,7,8}$ In our series, $3.0-\mathrm{mm}$ shunt size was associated with shunt thrombosis associated with acute events. Chittithavorn and colleagues ${ }^{7}$ noted higher rates of thrombosis in patients with 3.0-mm shunts, highlighting the dangers smaller shunts pose. Similar to Anderson and colleagues, ${ }^{8}$ we identified higher postoperative hematocrit to be associated with shunt thrombosis associated with acute events. Additionally, Sahoo and colleagues $^{21}$ demonstrated lowering intraoperative hematocrit reduced rates of shunt thrombosis. However, further research will be required to determine the optimal level for this strategy.

\section{Study Limitations}

Limitations include those inherent to the retrospective nature of this study, which may limit complete analysis of data related to shunt dysfunction and acute events. Rates of shunt-related complications including that of thrombosis are also likely an underestimate because true confirmation of thrombosis can only occur on shunt takedown or autopsy.

\section{CONCLUSIONS}

S-PA shunts continue to be associated with significant morbidity and mortality because more than one-fifth of children shunted during univentricular palliation will not survive before the next stage. Acute events in the early postoperative period are implicated in the majority of these deaths, with shunt thrombosis identified as an important factor. Shunt thrombosis associated with acute events 
seemed to be determined not only by smaller shunts but also by perioperative factors. Strategies to improve survival may include lower postoperative hematocrit and higher $\mathrm{pH}$ to promote shunt flow.

\section{Webcast}

You can watch a Webcast of this AATS meeting presentation by going to: https://aats.blob.core.windows.net/ media/18Apr29/30ABC\%20Congenital\%20SS/S52_2.mp4.

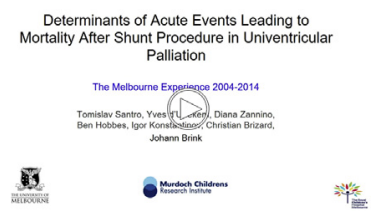

\section{Conflict of Interest Statement}

Brizard is a member of the Admedus Advisory Board. All other authors have nothing to disclose with regard to commercial support.

\section{References}

1. McKenzie ED, Khan MS, Samayoa AX, Vener DS, Ishak YM, Santos AB, et al. The Blalock-Taussig shunt revisited: a contemporary experience. J Am Coll Surg. 2013;216:699-706.

2. Bove T, Vandekerckhove K, Panzer J, De Groote K, De Wolf D, Francois K. Disease-specific outcome analysis of palliation with the modified Blalock-Taussig shunt. World J Pediatr Congenit Heart Surg. 2014;6:67-74.

3. Petrucci O, O'Brien SM, Jacobs ML, Jacobs JP, Manning PB, Eghtesady P. Risk factors for mortality and morbidity after the neonatal Blalock-Taussig shunt procedure. Ann Thorac Surg. 2011;92:642-51.

4. Alsoufi B, Gillespie S, Mori M, Clabby M, Kanter K, Kogon B. Factors affecting death and progression towards next stage following modified Blalock-Taussig shunt in neonates. Eur J Cardiothorac Surg. 2016;50:169-77.

5. Fenton KN, Siewers RD, Rebovich B, Pigula FA. Interim mortality in infants with systemic-to-pulmonary artery shunts. Ann Thorac Surg. 2003;76:152-6.

6. Alsoufi B, Gillespie S, Kogon B, Schlosser B, Sachdeva R, Kim D, et al. Results of palliation with an initial modified Blalock-Taussig shunt in neonates with single ventricle anomalies associated with restrictive pulmonary blood flow. Ann Thorac Surg. 2015;99:1639-46.

7. Chittithavorn V, Duangpakdee P, Rergkliang C, Pruekprasert N. Risk factors for in-hospital shunt thrombosis and mortality in patients weighing less than $3 \mathrm{~kg}$ with functionally univentricular heart undergoing a modified Blalock-Taussig shunt. Interact Cardiovasc Thorac Surg. 2017;25:407-13.

8. Anderson BR, Blancha VL, Duchon JM, Chai PJ, Kalfa D, Bacha EA, et al. The effects of postoperative hematocrit on shunt occlusion for neonates undergoing single ventricle palliation. J Thorac Cardiovasc Surg. 2017;153: 947-55.

9. Gates RN, Laks H, Johnson K. Side-to-side aorto-Gore-Tex central shunt. Ann Thorac Surg. 1998;65:515-6.

10. Brink J, MacIver R, Lee MG, Konstantinov IE, Cheung M, Brizard CP, et al. Neonatal pulmonary artery reconstruction during shunting to treat and prevent juxtaductal coarctation. Ann Thorac Surg. 2015;99:641-7.

11. Dorobantu DM, Pandey R, Sharabiani MT, Mahani AS, Angelini GD, Martin RP, et al. Indications and results of systemic to pulmonary shunts: results from a national database. Eur J Cardiothorac Surg. 2016;49:1553-63.

12. Myers JW, Ghanayem NS, Cao Y, Simpson P, Trapp K, Mitchell ME, et al. Outcomes of systemic to pulmonary artery shunts in patients weighing less than $3 \mathrm{~kg}$ : analysis of shunt type, size, and surgical approach. J Thorac Cardiovasc Surg. 2014;147:672-7.

13. Singh SP, Chauhan S, Choudhury M, Malik V, Talwar S, Hote MP, et al. Modified Blalock Taussig shunt: comparison between neonates, infants and older children. Ann Card Anaesth. 2014;17:191-7.
14. O'Connor MJ, Ravishankar C, Ballweg JA, Gillespie MJ, Gaynor JW, Tabbutt S, et al. Early systemic-to-pulmonary artery shunt intervention in neonates with congenital heart disease. J Thorac Cardiovasc Surg. 2011;142:106-12.

15. Mohammadi S, Benhameid O, Campbell A, Potts J, Joza J, Al-Habib H, et al Could we still improve early and interim outcome after prosthetic systemicpulmonary shunt? A risk factors analysis. Eur J Cardiothorac Surg. 2008;34: 545-9.

16. Alkhulaifi AM, Lacour-Gayet F, Serraf A, Belli E, Planche C. Systemic pulmonary shunts in neonates: early clinical outcome and choice of surgical approach. Ann Thorac Surg. 2000;69:1499-504.

17. Dirks V, Pretre R, Knirsch W, Valsangiacomo Buechel ER, Seifert B Schweiger M, et al. Modified Blalock Taussig shunt: a not-so-simple palliative procedure. Eur J Cardiothorac Surg. 2013;44:1096-102.

18. Alsoufi B, McCracken C, Schlosser B, Sachdeva R, Well A, Kogon B, et al. Outcomes of multistage palliation of infants with functional single ventricle and heterotaxy syndrome. J Thorac Cardiovasc Surg. 2016;151:1369-77.

19. Asakai H, Galati JC, Weskamp S, Jones B, Millar J, Konstantinov IE, et al. Impact of Blalock-Taussig shunt size on tricuspid regurgitation in hypoplastic left heart syndrome. Ann Thorac Surg. 2014;97:2123-8.

20. Alsoufi B, Mori M, Gillespie S, Schlosser B, Slesnick T, Kogon B, et al. Impact of patient characteristics and anatomy on results of Norwood operation for hypoplastic left heart syndrome. Ann Thorac Surg. 2015;100:591-8.

21. Sahoo TK, Chauhan S, Sahu M, Bisoi A, Kiran U. Effects of hemodilution on outcome after modified Blalock-Taussig shunt operation in children with cyanotic congenital heart disease. J Cardiothorac Vasc Anesth. 2007;21:179-83.

Key Words: shunt, univentricular heart/circulation, mortality, acute events, congenital heart surgery

\section{Discussion}

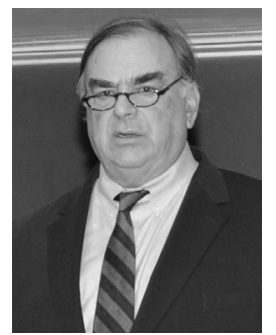

Dr M. Jacobs (Baltimore, Md). Dr Brink and colleagues in Melbourne have reported on associations among acute postoperative events, shunt failure associated with acute events, and mortality after palliative shunt procedures in patients with univentricular cardiac anomalies. This is certainly an important topic. The spectrum of functionally univentricular hearts represents a large and challenging segment of the overall congenital heart disease population, and their management involves arguably the largest fraction of human and institutional resources.

Shunt procedures are technically demanding, and the resultant physiology is potentially labile, being prone to maldistribution of blood flow from the single ventricle to the systemic and the pulmonary circulations. Although we may think of a particular shunt as being "too large" or "too small," we should realize that the same polytetrafluoroethylene tube graft may carry excessive flow to the lungs at one point in time, diminished flow to the lungs at another point in time, and we must also appreciate that these circumstances may be separated only by minutes.

Dr Brink, in your review of approximately 300 patients over a 10-year period, you demonstrated that among the 1 of 5 patients who died before reaching the superior cavopulmonary anastomosis stage, the majority of the deaths 
were associated with an acute event after surgery. Of the 79 patients who had an acute event, 40 required shunt reintervention, either immediately or thereafter. Your multivariable analysis revealed that the following were risk factors for acute events: higher preoperative platelet count and higher postoperative activated partial thromboplastin time. The risk factors for shunt thrombosis associated with an acute event were 3-mm shunt size and higher postoperative hematocrit. Of the 293 patients, 186 received platelets during surgery. In addition, 245 received additional clotting factors intraoperatively: fresh-frozen plasma in 212 patients and cryoprecipitate in 102 patients. Most patients received aprotinin or tranexamic acid.

All of this conveys a picture in which the delicate balance of pulmonary and systemic blood flow may fall victim to an unnatural imbalance between the goals of surgical hemostasis and avoidance of a thrombophilic state. Apart from the theoretical risk of shunt thrombosis, there is the inevitable effect of administration of products such as platelet concentrates on the ratio of systemic and pulmonary vascular resistances.

Have you considered that the situation might be favorably altered by a strategy based on the use of fresh whole blood as the principal agent to restore clotting function and to achieve surgical hemostasis, thereby maintaining a relatively physiologic balance of red cell and non-red cell components, and of natural procoagulant and anticoagulant factors? It is possible that such a strategy could minimize the requirement for transfusion of platelet concentrates and other clotting factors.

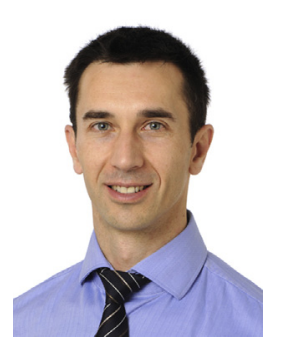

Dr Brink (Melbourne, Australia). We have not considered fresh whole blood. Dr Jacobs. Would fresh whole blood be available to you? I know it is sometimes a difficult resource to obtain.

Dr Brink. I am not sure. We used to have whole blood specially prepared, fresh heparinized blood, in the past, but that was discontinued about 6 years ago.

Dr Jacobs. I ask this question simply because it appears that the intraoperative use of these many clotting factors may contribute to a prothrombotic state, which may in turn contribute to the occurrence of these early postoperative events.

Dr Brink. I think the reason for using these clotting agents is if you take the whole group into account, approximately 200 patients were in Norwood/DKS status, so it's not just shunt in isolation. So to require extra clotting factors is somewhat reasonable.

Dr Jacobs. Of course. In that regard, we recently reported on an analysis of factors associated with early shunt failure among 9000 patients in the Society of Thoracic Surgeons Congenital Heart Surgery Database. We observed that the overall rate of early shunt failure was $7.3 \%$. For non-HLHS single ventricle patients it was $7.8 \%$, and for non-single ventricle anomalies it was virtually the same, at $7.7 \%$. Among patients undergoing the Norwood procedure, the rate of shunt failure was slightly lower, at $6.6 \%$. In our study that was reflective of a relatively lower incidence of shunt failure with the RV-PA shunt (5.2\%), relative to the modified BT shunt or other systemic artery-to-pulmonary artery shunt $(9.4 \%)$.

You mentioned that 46 patients in your cohort, or about 1 in 6, received RV-PA conduits as their systemic-to- pulmonary shunt. It would be interesting to know whether you undertook a subcohort analysis to see whether the rate of occurrence of acute events, the occurrence of shunt failure, or the risk factors for those events were different in the RV-PA conduit group versus the S-PA shunt group. Did you look specifically at the RV-PA shunt group?

Dr Brink. Yes, we had a look at that and could not find any significant difference for shunt type for acute events nor for thrombosis.

Dr Jacobs. That's interesting. My last question goes to your finding that the 3-mm shunt size was among the risk factors for shunt thrombosis associated with an acute event, apparently independent of shunt size-to-body weight ratio. I infer from your article that you are concerned about avoiding the circumstance that you have referred to as "pulmonary over-circulation." Given the findings of your study, what are your thoughts about the use of polytetrafluoroethylene shunts in the smallest sizes? Should an alternative graft such as cryopreserved saphenous vein be considered?

Dr Brink. In our unit, we use the RV-PA conduit in patients weighing $2.5 \mathrm{~kg}$ and less. We use a $5-\mathrm{mm}$ polytetrafluoroethylene (Gore-Tex) graft; if less than 2, then we use a 4-mm Gore-Tex graft. So there is a dilemma in a small patient with a high shunt/weight ratio. In our hands, the MBT shunt works well for us, but it is true, it has a risk for thrombosis and we cannot avoid that. That is the dilemma with small-weight patients.

Dr Jacobs. On behalf of all of us here, I want to say that over the years, we have learned a great deal from the careful clinical research done in your unit in Melbourne. Thank you so much for that.

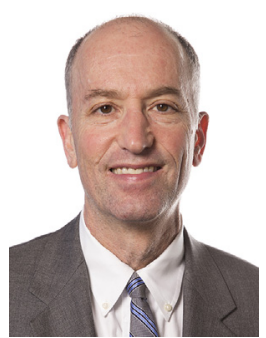

Dr W. Douglas (Kansas City, Mo). Did I catch it correctly that the median age of operation was 3 days?

Dr Brink. Yes. The mean age was 3 days, and the mean weight was $3.3 \mathrm{~kg}$.

Dr Douglas. I think most of us probably try to operate relatively early on these neonates who present, but 3 days is on the early side. Can you tell me how you came to that? That must be 
a deliberate policy. Has that changed over the last 10 years, or what drove you to so strictly operate at such a young age?

Dr Brink. The cohort is represented by univentricular palliation with a large number of patients that constitute Norwood/DKS subgroup. We don't have analysis of different eras.

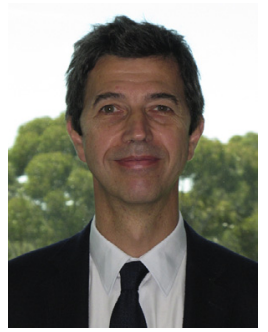

Dr C. Brizard (Melbourne, Australia). We do operate on hypoplasts at approximately 2 to 3 days of age, and approximately half of these patients are hypoplasts.

Dr S. Sano (Okayama, Japan). I missed your presentation, the first part. Can you explain postoperative management, because with these patients, management is a bit different, especially like single ventricle palliation. The resistance between the systemic and the pulmonary is key. So do you keep sedation, not only like fentanyl for the muscle relaxant for 1 or 2 days or just only the fentanyl? And the other thing is, when do you start an anticoagulant? I believe that you do start heparin, and do you use aspirin or warfarin or other anticoagulant therapies in the intensive care unit and long term?

Dr Brink. So the first question regarding the sedation, $72 \%$ of these patients have their chest left open after surgery. Our policy in the Norwood and DKS procedure is to have a delayed chest closure. So in these cases, the children will be well sedated and fentanyl is part of the regimen, and eventually, unless you want the heart stabilized, we close the chest.

Regarding the anticoagulation, once these children are admitted to the intensive care unit, we will commence heparin provided they are not bleeding. We start the dose at 10 to $15 \mathrm{U} / \mathrm{kg}$, and lately we have become a bit more aggressive in the case when they are not bleeding to commence the heparin in the operating room to avoid thrombotic effect. Aspirin and clopidogrel are the agents that we use later. We don't use warfarin. We commence aspirin for all shunts once they are enterally tolerated, and we add clopidogrel for 3- and 3.5-mm wrap shunts because we know that in children there is up to $80 \%$ aspirin resistance, especially in neonates, and therefore we add clopidogrel to cover them.

Dr Sano. One of the reasons why I have developed the RV-PA shunt and after I was back from Melbourne, I did a classic Norwood with sedation. Quite often, even with sedation, if the intensive care patient had sedation with fentanyl, when the diagnosis is infection, then the babies respond; they definitely change. So I ask to keep them sedated and use the muscle relaxants, so paralyzed completely, and then the resistance is stable and the shunt-related complications are less. I presented a paper at the last meeting of the World Congress, not single ventricle patients, and I have no early or late deaths since I changed the process.

Dr Brink. I am glad you made this comment. After reviewing all the data, which are complicated, because there are many variations in the formula determining shunt flow. One of these factors is resistance, which is difficult to monitor and manage. There are many patients for whom, when reviewing the medical records, we have no answer of what actually happened, and my suspicion is that fluctuation in pulmonary resistance is probably part of the issue.

Unidentified speaker. Just a quick comment. In the kids in whom we do end up using a 3-mm polytetrafluoroethylene shunt, we would heparinize them and they would go home with enoxaparin sodium, and in the last couple of years we have also performed the Norwood surgery earlier. So the average is probably 2 to 3 days of life, and I think that helps. 
TABLE E1. Univariable and multivariable risk factor analysis for 30-day mortality

\begin{tabular}{|c|c|c|c|c|}
\hline \multirow[b]{2}{*}{ Variable } & \multicolumn{2}{|c|}{ Univariable analysis } & \multicolumn{2}{|c|}{ Multivariable analysis } \\
\hline & OR $(95 \%$ CI $)$ & $P$ value & OR $(95 \%$ CI $)$ & $P$ value \\
\hline \multicolumn{5}{|l|}{ Patient demographics } \\
\hline Age (per 10-d increase) & $1.00(0.73-1.12)$ & .98 & & \\
\hline Weight (per 0.1-kg decrease) & $1.11(1.01-1.22)$ & .03 & & \\
\hline Later era (2009-2014) & $0.83(0.31-2.18)$ & .7 & & \\
\hline \multicolumn{5}{|l|}{ Morphological diagnosis } \\
\hline HLHS & $0.28(0.06-0.88)$ & .03 & & \\
\hline PA-VSD & NE & $\mathrm{NE}$ & & \\
\hline PA-IVS & $1.96(0.53-5.91)$ & .3 & & \\
\hline DORV & $2.72(0.40-11.5)$ & .3 & & \\
\hline DILV & NE & $\mathrm{NE}$ & & \\
\hline Tricuspid atresia & $0.55(0.03-2.89)$ & .5 & & \\
\hline AVSD & $0.69(0.11-2.57)$ & .6 & & \\
\hline Ebstein's anomaly & $9.37(1.17-60.6)$ & .04 & & \\
\hline Associated cardiac diagnosis & $0.53(0.20-1.41)$ & .2 & & \\
\hline Heterotaxy syndrome & $0.97(0.15-3.68)$ & .97 & & \\
\hline Extracardiac or genetic anomaly & $1.74(0.58-4.71)$ & .3 & & \\
\hline \multicolumn{5}{|l|}{ Preoperative factors } \\
\hline Mechanical ventilation & $4.14(1.54-12.3)$ & .005 & & \\
\hline Shock/acidosis & $2.86(1.08-7.80)$ & .03 & & \\
\hline ECMO & $28.2(2.58-627)$ & .01 & & \\
\hline Hemoglobin (per $10 \mathrm{~g} / \mathrm{L}$ increase) & $0.71(0.56-0.89)$ & .002 & & \\
\hline Hematocrit (per 0.1-unit increase) & $0.26(0.11-0.63)$ & .001 & $0.32(0.12-0.77)$ & .017 \\
\hline Platelets (per $100 \times 10^{9} / \mathrm{L}$ increase) & $1.05(0.69-1.59)$ & .8 & & \\
\hline \multicolumn{5}{|l|}{ Shunt type } \\
\hline MBTS & $0.33(0.09-1.53)$ & .1 & & \\
\hline Central & $2.84(0.61-9.86)$ & .2 & & \\
\hline \multicolumn{5}{|l|}{ Shunt size } \\
\hline $3.0 \mathrm{~mm}$ & $1.07(0.38-2.82)$ & .9 & & \\
\hline $3.5 \mathrm{~mm}$ & $0.94(0.36-2.55)$ & .9 & & \\
\hline $4.0 \mathrm{~mm}$ & $1.06(0.06-5.89)$ & .96 & & \\
\hline $5.0 \mathrm{~mm}$ & NE & & & \\
\hline Shunt size to weight ratio (per 0.1 -unit increase) & $1.50(1.16-1.95)$ & .003 & & \\
\hline \multicolumn{5}{|l|}{ Intraoperative factors } \\
\hline Norwood/DKS procedure & $0.38(0.13-1.00)$ & .05 & & \\
\hline Concomitant procedure & $0.69(0.25-2.25)$ & .5 & & \\
\hline Intraoperative shunt wrapping & $2.05(0.63-5.82)$ & .2 & & \\
\hline Platelets given & $1.06(0.39-3.17)$ & .9 & & \\
\hline FFP or cryoprecipitate given & $0.63(0.21-2.34)$ & .5 & & \\
\hline Aprotinin given & $0.81(0.29-2.18)$ & .7 & & \\
\hline Tranexamic acid given & $0.89(0.24-2.62)$ & .8 & & \\
\hline Use of $\mathrm{CPB}$ & $0.51(0.15-2.31)$ & .3 & & \\
\hline CPB time (per 10-min increase) & $1.03(0.98-1.08)$ & .3 & & \\
\hline \multicolumn{5}{|l|}{ Postoperative factors } \\
\hline Incidence of an acute event & $7.73(2.74-25.2)$ & $<.001$ & $6.57(2.28-21.8)$ & .001 \\
\hline Early acute event & $1.31(0.36-5.43)$ & .7 & & \\
\hline Use of ECMO & $8.58(3.14-24.2)$ & $<.001$ & & \\
\hline Shunt reintervention & $0.96(0.26-2.85)$ & .9 & & \\
\hline
\end{tabular}

Bold denotes statistical significance $(P<.05)$. Continuous variables are presented as an OR per unit increase/decrease. $O R$, Odds ratio; $C I$, confidence interval; $H L H S$, hypoplastic left heart syndrome; $P A-V S D$, pulmonary atresia with ventricular septal defect; $N E$, not estimated; $P A-I V S$, pulmonary atresia with intact ventricular septum; $D O R V$, double outlet right ventricle; $D I L V$, double inlet left ventricle; $A V S D$, atrioventricular septal defect; $E C M O$, extracorporeal membrane oxygen; $M B T S$, modified Blalock-Taussig shunt; $D K S$, Damus-Kaye-Stansel; $F F P$, fresh-frozen plasma; $C P B$, cardiopulmonary bypass. 
TABLE E2. Univariable and multivariable risk factor analysis for in-hospital mortality

\begin{tabular}{|c|c|c|c|c|}
\hline \multirow[b]{2}{*}{ Variable } & \multicolumn{2}{|c|}{ Univariable analysis } & \multicolumn{2}{|c|}{ Multivariable analysis } \\
\hline & OR $(95 \%$ CI $)$ & $P$ value & OR $(95 \% \mathrm{CI})$ & $P$ value \\
\hline \multicolumn{5}{|l|}{ Patient demographics } \\
\hline Age (per 10-d increase) & $0.91(0.68-1.21)$ & .4 & & \\
\hline Weight (per $0.1 \mathrm{~kg}$ decrease) & $1.06(1.00-1.14)$ & .09 & & \\
\hline Later era (2009-2014) & $0.93(0.45-1.89)$ & .8 & & \\
\hline \multicolumn{5}{|l|}{ Morphological diagnosis } \\
\hline HLHS & $0.95(0.45-1.95)$ & .9 & & \\
\hline PA-VSD & $\mathrm{NE}$ & $\mathrm{NE}$ & & \\
\hline PA-IVS & $1.05(0.34-2.72)$ & .9 & & \\
\hline DORV & $3.16(0.81-10.6)$ & .09 & & \\
\hline DILV & $\mathrm{NE}$ & $\mathrm{NE}$ & & \\
\hline Tricuspid atresia & $0.53(0.08-1.92)$ & .4 & & \\
\hline AVSD & $0.90(0.29-2.31)$ & .8 & & \\
\hline Ebstein's anomaly & $4.06(0.52-25.4)$ & .2 & & \\
\hline Associated cardiac diagnosis & $0.98(0.48-2.10)$ & .96 & & \\
\hline Heterotaxy syndrome & $0.67(0.15-2.06)$ & .5 & & \\
\hline Extracardiac or genetic anomaly & $1.12(0.47-2.48)$ & .8 & & \\
\hline \multicolumn{5}{|l|}{ Preoperative factors } \\
\hline Mechanical ventilation & $2.07(1.01-4.26)$ & .047 & & \\
\hline Shock/acidosis & $2.43(1.18-5.00)$ & .02 & & \\
\hline ECMO & $12.2(1.14-268)$ & .04 & & \\
\hline Hemoglobin (per $10 \mathrm{~g} / \mathrm{L}$ increase) & $0.85(0.73-0.99)$ & .03 & & \\
\hline Hematocrit (per 0.1-unit increase) & $0.56(0.33-0.95)$ & .025 & & \\
\hline Platelets (per $100 \times 10^{9} / \mathrm{L}$ increase) & $1.00(0.73-1.37)$ & .99 & & \\
\hline \multicolumn{5}{|l|}{ Shunt type } \\
\hline MBTS & $0.79(0.24-3.54)$ & .7 & & \\
\hline Central & $1.18(0.26-3.83)$ & .8 & & \\
\hline \multicolumn{5}{|l|}{ Shunt size } \\
\hline $3.0 \mathrm{~mm}$ & $0.70(0.32-1.47)$ & .4 & & \\
\hline $3.5 \mathrm{~mm}$ & $1.62(0.78-3.51)$ & .2 & & \\
\hline $4.0 \mathrm{~mm}$ & $0.47(0.03-2.51)$ & .4 & & \\
\hline $5.0 \mathrm{~mm}$ & $\mathrm{NE}$ & & & \\
\hline Shunt size to weight ratio (per 0.1-unit increase) & $1.31(1.06-1.61)$ & .013 & & \\
\hline \multicolumn{5}{|l|}{ Intraoperative factors } \\
\hline Norwood/DKS procedure & $0.88(0.43-1.83)$ & .7 & & \\
\hline Concomitant procedure & $1.16(0.50-3.04)$ & .7 & & \\
\hline Intraoperative shunt wrapping & $1.53(0.61-3.53)$ & .3 & & \\
\hline Platelets given & $0.97(0.47-2.08)$ & .9 & & \\
\hline FFP or cryoprecipitate given & $0.97(0.40-2.75)$ & .9 & & \\
\hline Aprotinin given & $1.46(0.71-3.08)$ & .3 & & \\
\hline Tranexamic acid given & $0.84(0.34-1.89)$ & .7 & & \\
\hline Use of CPB & $0.84(0.29-3.04)$ & .8 & & \\
\hline CPB Time (per 10-min increase) & $1.10(1.04-1.16)$ & $<.001$ & $1.10(1.04-1.16)$ & .002 \\
\hline \multicolumn{5}{|l|}{ Postoperative factors } \\
\hline Incidence of an acute event & $14.8(6.51-37.2)$ & $<.001$ & $13.5(5.51-36.4)$ & $<.001$ \\
\hline Early acute event & $0.85(0.31-2.36)$ & .8 & & \\
\hline Use of ECMO & $12.6(5.66-28.8)$ & $<.001$ & & \\
\hline Shunt re-intervention & $1.54(0.68-3.30)$ & .3 & & \\
\hline
\end{tabular}

Bold denotes statistical significance $(P<.05)$. Continuous variables are presented as an OR per unit increase/decrease. $O R$, Odds ratio; $C I$, confidence interval; $H L H S$, hypoplastic left heart syndrome; $P A-V S D$, pulmonary atresia with ventricular septal defect; $N E$, not estimated; $P A-I V S$, pulmonary atresia with intact ventricular septum; $D O R V$, double outlet right ventricle; $D I L V$, double inlet left ventricle; $A V S D$, atrioventricular septal defect; $E C M O$, extracorporeal membrane oxygen; MBTS, modified Blalock-Taussig shunt; $D K S$, Damus-Kaye-Stansel; $F F P$, fresh-frozen plasma; $C P B$, cardiopulmonary bypass. 
TABLE E3. Univariable and multivariable risk factor analysis for acute events

\begin{tabular}{|c|c|c|c|c|}
\hline \multirow[b]{2}{*}{ Variable } & \multicolumn{2}{|c|}{ Univariable analysis } & \multicolumn{2}{|c|}{ Multivariable analysis } \\
\hline & OR $(95 \%$ CI $)$ & $P$ value & OR $(95 \%$ CI $)$ & $P$ value \\
\hline \multicolumn{5}{|l|}{ Patient demographics } \\
\hline Age (per 10-d increase) & $0.95(0.82-1.11)$ & .5 & & \\
\hline Weight (per $0.1 \mathrm{~kg}$ decrease) & $1.06(1.00-1.12)$ & .05 & & \\
\hline Later era (2009-2014) & $1.25(0.71-2.21)$ & .4 & & \\
\hline \multicolumn{5}{|l|}{ Morphological diagnosis } \\
\hline HLHS & $1.15(0.64-2.03)$ & 6 & & \\
\hline PA-VSD & $0.54(0.03-3.40)$ & .5 & & \\
\hline PA-IVS & $1.67(0.75-3.58)$ & .2 & & \\
\hline DORV & $2.88(0.87-9.55)$ & .08 & & \\
\hline DILV & $0.40(0.06-1.50)$ & .2 & & \\
\hline Tricuspid atresia & $0.73(0.23-1.93)$ & .5 & & \\
\hline AVSD & $0.71(0.29-1.59)$ & .4 & & \\
\hline Ebstein's anomaly & $0.90(0.04-7.19)$ & .9 & & \\
\hline Associated cardiac diagnosis & $1.25(0.69-2.31)$ & .5 & & \\
\hline Heterotaxy syndrome & $0.42(0.12-1.13)$ & .1 & & \\
\hline Extracardiac or genetic anomaly & $1.21(0.62-2.29)$ & 6 & & \\
\hline \multicolumn{5}{|l|}{ Preoperative factors } \\
\hline Mechanical ventilation & $1.56(0.87-2.79)$ & .1 & & \\
\hline Shock/acidosis & $1.72(0.95-3.10)$ & .1 & & \\
\hline ECMO & $1.35(0.06-14.4)$ & .8 & & \\
\hline Hemoglobin (per $10 \mathrm{~g} / \mathrm{L}$ increase) & $0.86(0.76-0.97)$ & .013 & & \\
\hline Hematocrit (per 0.1-unit increase) & $0.58(0.38-0.89)$ & .01 & $0.62(0.4-0.94)$ & .03 \\
\hline Platelets (per $100 \times 10^{9} / \mathrm{L}$ increase) & $1.25(0.98-1.60)$ & .08 & & \\
\hline \multicolumn{5}{|l|}{ Shunt type } \\
\hline MBTS & $2.72(0.73-17.6)$ & .1 & & \\
\hline Central & $0.34(0.05-1.26)$ & .1 & & \\
\hline \multicolumn{5}{|l|}{ Shunt size } \\
\hline $3.0 \mathrm{~mm}$ & $0.87(0.48-1.56)$ & .7 & & \\
\hline $3.5 \mathrm{~mm}$ & $1.45(0.81-2.61)$ & .2 & & \\
\hline $4.0 \mathrm{~mm}$ & $0.21(0.01-1.12)$ & .1 & & \\
\hline $5.0 \mathrm{~mm}$ & $\mathrm{NE}$ & & & \\
\hline Shunt size to weight ratio (per 0.1-unit increase) & $1.28(1.06-1.55)$ & .01 & & \\
\hline \multicolumn{5}{|l|}{ Intraoperative factors } \\
\hline Norwood/DKS procedure & $1.26(0.70-2.29)$ & .4 & & \\
\hline Concomitant procedure & $0.81(0.42-1.62)$ & 6 & & \\
\hline Intraoperative shunt wrapping & $1.81(0.87-3.67)$ & .1 & & \\
\hline Platelets given & $0.82(0.46-1.47)$ & .5 & & \\
\hline FFP or cryoprecipitate given & $1.01(0.49-2.24)$ & .97 & & \\
\hline Aprotinin given & $0.86(0.48-1.51)$ & .6 & & \\
\hline Tranexamic acid given & $1.58(0.84-2.95)$ & .2 & & \\
\hline Use of CPB & $0.71(0.30-1.84)$ & .5 & & \\
\hline CPB Time (per 10-min increase) & $1.03(0.99-1.06)$ & .1 & & \\
\hline \multicolumn{5}{|l|}{ Operative data (last in theatre) } \\
\hline $\mathrm{pH}$ (per 0.1-unit increase) & $0.55(0.39-0.76)$ & $<.001$ & & \\
\hline $\mathrm{PaCO}_{2}$ (per 10-unit increase) & $1.29(0.95-1.74)$ & .1 & & \\
\hline $\mathrm{PaO}_{2}$ (per 100-unit increase) & $1.15(0.75-1.75)$ & .4 & & \\
\hline Lactate (per 5-unit increase) & $1.34(0.72-2.51)$ & .4 & & \\
\hline Hemoglobin (per $10 \mathrm{~g} / \mathrm{L}$ increase) & $1.14(0.99-1.31)$ & .07 & & \\
\hline ACT (per 10-unit increase) & $1.11(1.03-1.19)$ & .003 & & \\
\hline \multicolumn{5}{|l|}{ Postoperative data (first in ICU) } \\
\hline $\mathrm{pH}$ (per 0.1-unit increase) & $0.59(0.44-0.80)$ & $<.001$ & $0.61(0.45-0.82)$ & .002 \\
\hline $\mathrm{PaCO}_{2}$ (per 10-unit increase) & $1.32(1.01-1.73)$ & .04 & & \\
\hline
\end{tabular}




\begin{tabular}{|c|c|c|c|c|}
\hline \multirow[b]{2}{*}{ Variable } & \multicolumn{2}{|c|}{ Univariable analysis } & \multicolumn{2}{|c|}{ Multivariable analysis } \\
\hline & OR $(95 \%$ CI $)$ & $P$ value & OR $(95 \%$ CI $)$ & $P$ value \\
\hline $\mathrm{PaO}_{2}$ (per 100-unit increase) & $1.29(0.76-2.19)$ & .4 & & \\
\hline Lactate (per 5-unit increase) & $0.98(0.85-1.12)$ & .7 & & \\
\hline Hemoglobin (per $10 \mathrm{~g} / \mathrm{L}$ increase) & $1.08(0.94-1.24)$ & .3 & & \\
\hline Hematocrit (per 0.1-unit increase) & $1.40(0.88-2.22)$ & .2 & & \\
\hline Platelets (per $100 \times 10^{9} / \mathrm{L}$ increase) & $1.20(0.88-1.65)$ & .3 & & \\
\hline INR (per 0.1-unit increase) & $1.05(0.96-1.14)$ & .3 & & \\
\hline APTT (per 10-unit increase) & $1.13(1.06-1.22)$ & $<.001$ & $1.12(1.04-1.20)$ & .002 \\
\hline Platelets given & $1.71(0.87-3.30)$ & .1 & & \\
\hline
\end{tabular}

Bold denotes statistical significance $(P<.05)$. Continuous variables are presented as an OR per unit increase/decrease. $O R$, Odds ratio; $C I$, confidence interval; $H L H S$, hypoplastic left heart syndrome; $P A-V S D$, pulmonary atresia with ventricular septal defect; $P A-I V S$, pulmonary atresia with intact ventricular septum; $D O R V$, double outlet right ventricle; $D I L V$, double inlet left ventricle; $A V S D$, atrioventricular septal defect; $E C M O$, extracorporeal membrane oxygen; MBTS, modified Blalock-Taussig shunt; NE, not estimated; $\mathrm{DKS}$, Damus-Kaye-Stansel; $\mathrm{FFP}$, fresh-frozen plasma; $\mathrm{CPB}$, cardiopulmonary bypass; $\mathrm{pH},-\log 10[\mathrm{H}+] ; \mathrm{PaCO}_{2}$, partial pressure arterial carbon dioxide; $\mathrm{PaO} 2$, partial pressure arterial oxygen; $A C T$, activated clotting time; $I C U$, intensive care unit; $I N R$, international normalized ratio; $A P T T$, activated partial thromboplastin time. 
TABLE E4. Univariable and multivariable risk factor analysis for shunt thrombosis associated with acute events

\begin{tabular}{|c|c|c|c|c|}
\hline \multirow[b]{2}{*}{ Variable } & \multicolumn{2}{|c|}{ Univariable analysis } & \multicolumn{2}{|c|}{ Multivariable analysis } \\
\hline & OR $(95 \%$ CI $)$ & $P$ value & OR $(95 \%$ CI $)$ & $\overline{P \text { value }}$ \\
\hline \multicolumn{5}{|l|}{ Patient demographics } \\
\hline Age (per 10-d increase) & $0.80(0.46-1.39)$ & .3 & & \\
\hline Weight (per 0.1-kg decrease) & $0.45(0.18-1.09)$ & .063 & & \\
\hline Later era (2009-2014) & $2.64(1.02-7.68)$ & .045 & & \\
\hline \multicolumn{5}{|l|}{ Morphological diagnosis } \\
\hline HLHS & $2.44(0.97-6.46)$ & .058 & & \\
\hline PA-VSD & NE & & & \\
\hline PA-IVS & $1.15(0.26-3.70)$ & .8 & & \\
\hline DORV & $1.03(0.05-5.74)$ & .98 & & \\
\hline DILV & $0.80(0.04-4.31)$ & .8 & & \\
\hline Tricuspid atresia & $1.08(0.17-4.12)$ & .9 & & \\
\hline AVSD & $0.28(0.02-1.41)$ & .14 & & \\
\hline Ebstein's anomaly & $\mathrm{NE}$ & & & \\
\hline Associated cardiac diagnosis & $0.82(0.33-2.18)$ & .7 & & \\
\hline Heterotaxy syndrome & $0.39(0.02-1.99)$ & .3 & & \\
\hline Extracardiac or genetic anomaly & $1.12(0.35-3.03)$ & .8 & & \\
\hline \multicolumn{5}{|l|}{ Preoperative factors } \\
\hline Mechanical ventilation & $0.78(0.27-2.02)$ & .6 & & \\
\hline Shock/acidosis & $1.14(0.41-2.92)$ & .8 & & \\
\hline ECMO & $\mathrm{NE}$ & & & \\
\hline Hemoglobin (per $10 \mathrm{~g} / \mathrm{L}$ increase) & $0.93(0.76-1.13)$ & .434 & & \\
\hline Hematocrit (per 0.1-unit increase) & $0.77(0.40-1.49)$ & .426 & & \\
\hline Platelets (per $100 \times 10^{9} / \mathrm{L}$ increase) & $1.36(0.94-1.97)$ & .122 & & \\
\hline \multicolumn{5}{|l|}{ Shunt type } \\
\hline MBTS & NE & & & \\
\hline Central & NE & & & \\
\hline \multicolumn{5}{|l|}{ Shunt size } \\
\hline $3.0 \mathrm{~mm}$ & $3.46(1.36-9.52)$ & .009 & $3.78(1.47-10.6)$ & .007 \\
\hline $3.5 \mathrm{~mm}$ & $0.38(0.14-0.96)$ & .04 & & \\
\hline $4.0 \mathrm{~mm}$ & $\mathrm{NE}$ & & & \\
\hline $5.0 \mathrm{~mm}$ & $\mathrm{NE}$ & & & \\
\hline Shunt size to weight ratio (per 0.1-unit increase) & $1.94(0.12-31.36)$ & .6 & & \\
\hline \multicolumn{5}{|l|}{ Intraoperative factors } \\
\hline Norwood/DKS procedure & $1.54(0.60-4.50)$ & .4 & & \\
\hline Concomitant procedure & $1.61(0.51-7.09)$ & .44 & & \\
\hline Platelets given & $2.45(0.87-8.78)$ & .1 & & \\
\hline FFP or cryoprecipitate given & $1.90(0.52-12.24)$ & .4 & & \\
\hline Aprotinin given & $0.59(0.22-1.48)$ & .3 & & \\
\hline Tranexamic acid given & $3.27(1.28-8.39)$ & .014 & & \\
\hline Use of CPB & $\mathrm{NE}$ & & & \\
\hline CPB time (per 10-min increase) & $0.98(0.93-1.04)$ & 6 & & \\
\hline \multicolumn{5}{|l|}{ Operative data (last in theatre) } \\
\hline $\mathrm{pH}$ (per 0.1-unit increase) & $0.22(0.00-28.62)$ & .5 & & \\
\hline $\mathrm{PaCO}_{2}$ (per 10-unit increase) & $1.32(0.82-2.13)$ & .25 & & \\
\hline $\mathrm{PaO}_{2}$ (per 100-unit increase) & $0.37(0.01-10.47)$ & .3 & & \\
\hline Lactate (per 5-unit increase) & $1.16(0.42-3.19)$ & .8 & & \\
\hline Hemoglobin (per $10 \mathrm{~g} / \mathrm{L}$ increase) & $1.05(0.84-1.30)$ & .7 & & \\
\hline ACT (per 10-unit increase) & $1.01(0.92-1.11)$ & .9 & & \\
\hline \multicolumn{5}{|l|}{ Postoperative data (first in ICU) } \\
\hline pH (per 0.1-unit increase) & $0.14(0.00-12.34)$ & .4 & & \\
\hline $\mathrm{PaCO}_{2}$ (per 10-unit increase) & $1.45(0.97-2.18)$ & .08 & & \\
\hline $\mathrm{PaO}_{2}$ (per 100-unit increase) & $0.52(0.03-7.91)$ & .5 & & \\
\hline
\end{tabular}


TABLE E4. Continued

\begin{tabular}{|c|c|c|c|c|}
\hline \multirow[b]{2}{*}{ Variable } & \multicolumn{2}{|c|}{ Univariable analysis } & \multicolumn{2}{|c|}{ Multivariable analysis } \\
\hline & OR $(95 \%$ CI $)$ & $P$ value & OR $(95 \%$ CI $)$ & $P$ value \\
\hline Lactate (per 5-unit increase) & $0.83(0.35-1.97)$ & .5 & & \\
\hline Hemoglobin (per $10 \mathrm{~g} / \mathrm{L}$ increase) & $1.21(0.97-1.52)$ & .1 & & \\
\hline Hematocrit (per 0.1-unit increase) & $1.96(0.93-4.14)$ & .074 & $2.12(1.01-4.58)$ & .049 \\
\hline Platelets (per $100 \times 10^{9} / \mathrm{L}$ increase) & $1.10(0.67-1.82)$ & .7 & & \\
\hline INR (per 0.1-unit increase) & $0.15(0.02-0.97)$ & .029 & & \\
\hline APTT (per 10-unit increase) & $1.05(0.95-1.17)$ & .4 & & \\
\hline Platelets given & $0.66(0.15-2.08)$ & .5 & & \\
\hline
\end{tabular}

Bold denotes statistical significance $(P<.05)$. Continuous variables are presented as an OR per unit increase/decrease. $O R$, Odds ratio; $C I$, confidence interval; $H L H S$, hypoplastic left heart syndrome; $P A-V S D$, pulmonary atresia with ventricular septal defect; $N E$, not estimated; $P A-I V S$, pulmonary atresia with intact ventricular septum; $D O R V$, double outlet right ventricle; $D I L V$, double inlet left ventricle; $A V S D$, atrioventricular septal defect; $E C M O$, extracorporeal membrane oxygen; $M B T S$, modified Blalock-Taussig shunt; $D K S$, Damus-Kaye-Stansel; $F F P$, fresh-frozen plasma; $\mathrm{CPB}$, cardiopulmonary bypass; $\mathrm{pH},-\log 10[\mathrm{H}+] ; \mathrm{PaCO}_{2}$, partial pressure arterial carbon dioxide; $\mathrm{PaO}_{2}$, partial pressure arterial oxygen; $A C T$, activated clotting time; $I C U$, intensive care unit; INR, international normalized ratio; $A P T T$, activated partial thromboplastin time. 